\title{
Simulasie van veilige projektielbewapening deur vliegwieltipe aanslagbuise
}

\author{
E. Fourie en F.J. van Graan* \\ Departement Meganiese en Lugvaartkundige Ingenieurswese, Universiteit van Pretoria, Pretoria, 0002
}

Ontvang 5 November 1995; aanvaar 15 April 1996

\section{UITTREKSEL}

'n Neusbuis word as aanslagbuis gebruik om 'n projektiel wat van 'n granaatwerper afgevuur word, te bewapen. 'n Neusbuis wat gebruik maak van 'n vliegwiel as meganisme wat deur vlugtyd of -afstand van die projektiel beheer word, is in konsep ontwikkel. As gevolg van eenvoud van werking en konstruksie word hoë betroubaarheid verwag.

Die dinamiese gedrag van al die komponente van die vliegwieltipe neusbuis is wiskundig gemodelleer. ' $n$ Simulasiepakket is ontwikkel, wat al die verskillende wiskundige modelle koppel. Deur die begin- en randwaardes kwantitatief te definieer, kan die gedrag van die projektiel, vliegwiel en ander komponente deurlopend vir afvuur-en vlugtoestande bereken word.

\section{Abstract}

\section{Dynamic simulation of flywheel-type fuses}

Rounds of ammunition are normally armed with a fuse. In this study, a fuse is developed which uses a flywheel-type mechanism controlled by time or distance. Due to its simplicity of operation and construction, the concept is expected to have high reliability.

The dynamic response of all the components of this flywheel-type fuse is mathematically modelled. Simulation software was developed which connects the mathematical models of the various components. With the definition of boundary values, the response of the projectile, flywheel and other components can be determined continuously for flring and in-flight conditions.

\section{INLEIDING}

'n Aanslagbuis het die doel om te verseker dat 'n projektiel, nadat dit afgevuur is, slegs bewapen word nadat die projektiel ' $n$ veilige afstand van die wapen af beweeg het. Die behoefte bestaan om 'n goedkoop, effektiewe aanslagbuis te ontwikkel vir ammunisie van klein kaliber granaatwerpers. Die hooffunksies van so 'n buis, wat verkieslik aan die voorpunt van die projektiel bevestig word en derhalwe as neusbuis bekend staan, is soos volg:

- Selfbewapening moet gebeur as gevolg van versnellingskragte tydens translasie en rotasie.

- Impakdetonasie moet plaasvind met enige botsing na bewapening.

'n Ondersoek na verskillende meganismes, insluitende elektroniese stelsels, is vir granaattipe ammunisie uitgevoer. Gedurende hierdie ondersoek is 'n meganisme ontdek wat sover vasgestel kon word, nie voorheen in aanslagbuise gebruik is nie: in beginsel bestaan dit uit 'n klein vliegwiel op 'n bewegingskroef in die hartlyn van die granaat. Sodra die granaat afgevuur word, onttrek die versnellingskrag 'n sluitpen sodat die vliegwiel vrylik op die skroef kan beweeg. Die traagheid van die vliegwiel veroorsaak dat die vliegwiel nie teen dieselfde spoed as die granaat roteer nie. Gevolglik skroef dit langs die as af totdat dit, na die gewenste tyd, die ladingstelsel bewapen vir ontploffing by impak.

'n Wiskundige ontleding en die simulasie van die beweging van die vliegwiel is gedoen om vas te stel of die tegniek betroubaar kan werk. Die projektielbeweging en die vliegwielgedrag is dinamies gesimuleer vir afvuring en vlugtoestande. Die vliegwiel se funksies is afgehandel voor impak en daarom word slegs die gedrag van die meganismes in die neusbuis voor impak ondersoek.

Die ontleding het getoon dat hierdie koste-effektiewe tegniek wel goed kan werk. Met behulp van die simulasiepakket kan die parameters van hierdie tipe meganismes vir derglike ontwerpe geoptimeer word.

\section{VLIEGWIELKONSEP VIR SELFBEWAPENING}

Daar bestaan streng veiligheidsvereistes vir aanslagbuise. Die meganismes wat selfbewapening veroorsaak, moet baie betroubaar funksioneer en enige faling mag geen gevaartoestand veroorsaak nie. Enige konsep of idee wat voldoen aan al die veiligheids- en betroubaarheidsvereistes met addisionele voordele, byvoorbeeld die verstelling van die bewapeningsafstand, het potensiaal vir verdere ontwikkeling.

'n Voorstudie het onder andere gelei tot 'n konsepontwerp wat gebruik maak van 'n vliegwiel. Die vliegwielbeginsel word kortliks met behulp van figuur 1 verduidelik.

By voldoende hoë translasieversnelling $x$ van die projektiel ontkoppel die sluitpen en kan die vliegwiel, met massa $\mathrm{m}$, op die skroefdraad roteer. As gevolg van die translasieversnelling ontstaan ' $n$ krag wat die vliegwiel teen die skroefdraad vasdruk. Die wrywing op die draad $\mu$, die versnellingskrag en die rotasiesnelheid $\dot{\theta}$ van die projektiel, veroorsaak ' $n$ moment $T_{F}$, wat met verloop van tyd die vliegwiel se hoeksnelheid $\Phi$ sal laat toeneem tot dié van die projektiel. Voordat dit egter gebeur, skroef die vliegwiel, weens die verskil in rotasiesnelheid van die projektiel en die vliegwiel, af tot onder. Die detonator word hierdeur ontsluit, sodat dit in lyn beweeg met die lading, gereed vir detonasie. 


\section{WISKUNDIGE ONTLEDING EN SIMULASIE}

\section{Algemeen}

Kragte wat op die neusbuis inwerk gedurende vlugtyd is die gevolg van translasieversnelling of -vertraging, rotasiebeweging, wrywing en veerkrag. Rotasie kan radiale, tangensiale en Corioliskragte veroorsaak, hetsy of 'n komponent onderhewig is aan rotasieversnelling of -vertraging of nie. Wrywingskragte wat enige beweging teëwerk, is afhanklik van die wrywingskoëffisiënt tussen die materiale wat teenmekaar beweeg en die krag waarmee twee voorwerpe teenmekaar gedruk word. In die voorafgaande geval is dit die massa van die vliegwiel vermenigvuldig met die versnellingskomponente gerig teen die skroefdraad (in die meeste ander gevalle is dit die gewig as massa vermenigvuldig met gravitasieversnelling!). Veerkragte kan as potensiële kragte in die stelsel ingebou word om onder sekere toestande 'n invloed te hê, byvoorbeeld om radiale kragte tydens rotasie te opponeer.

Model ten opsigte van aandrywing van die projektiel

Die translasieversnelling van die projektiel sal op alle komponente van die neusbuis ' $n$ invloed hê. Wanneer 'n projektiel afgevuur word is die translasieversnelling 'n direkte gevolg van die uitsetting van dryfmiddelgas wat resulteer in 'n veranderende druk. Die tipiese verloop van so 'n drukkromme word in figuur 2 voorgestel. 'n Drukpuls is eksperimenteel gemeet. 'n Passing is daarop gedoen met behulp van 'n Fourierreeks om 'n wiskundige vergelyking te verkry, waarmee die benaderde druk op enige tydstip tydens die puls vir simulasiedoeleindes bereken kan word. Die vergelyking vir 'n Fourierreeks om 'n benaderde druk $P_{b}$ te gee, is volgens Kreyszig: ${ }^{1}$

$$
P_{b}(t)=a_{o}+\sum_{j=1}^{n}\left(a_{j} \operatorname{Cos} \omega_{j} t+b_{j} \operatorname{Sin} \omega_{j} t\right)
$$

met $a_{0}$ wat die gemiddelde druk voorstel, terwyl $a_{\text {f }}$ en $b_{\text {, die }}$ drukamplitudes by elke frekwensie voorstel. Die frekwensies $\omega_{j}$ is veelvoude van die omgekeerde van die totale pulstyd T sodat

$$
\omega_{j}=\frac{2 \pi j}{T}
$$

Die onderskeie drukamplitudes word soos volg bereken:

$$
\begin{aligned}
& a_{o}=\frac{1}{T} \int_{0}^{T} P(t) d t \\
& a_{j}=\frac{2}{T} \int_{0}^{T} \int_{0} P(t) \operatorname{Cos} \omega_{j} t d t \\
& b_{j}=\frac{2}{T} \int_{0}^{T} P(t) \operatorname{Sin} \omega_{j} t d t
\end{aligned}
$$

Daar is gevind dat voldoende akkuraatheid bereik word as die Fourierreeks by $n=10$ afgebreek word.

\section{Wiskundige modelle vir die projektielbeweging}

Beide fases, $n l$. binne die wapenloop en gedurende vlugtyd word ontleed, omdat die bewapening afhanklik is van kragte wat geînduseer word as gevolg van rotasie en translasie gedurende hierdie fases.

\section{Wiskundige model van projektielbeweging binne die loop}

In figuur 3 word al die moontlike kragte wat op die projektiel inwerk, voorgestel vir die algemeenste geval waar die projektiel onderhewig is aan gasdruk, translasieversnelling, rotasieversnelling en loopgroefwrywing in die loopgedeelte

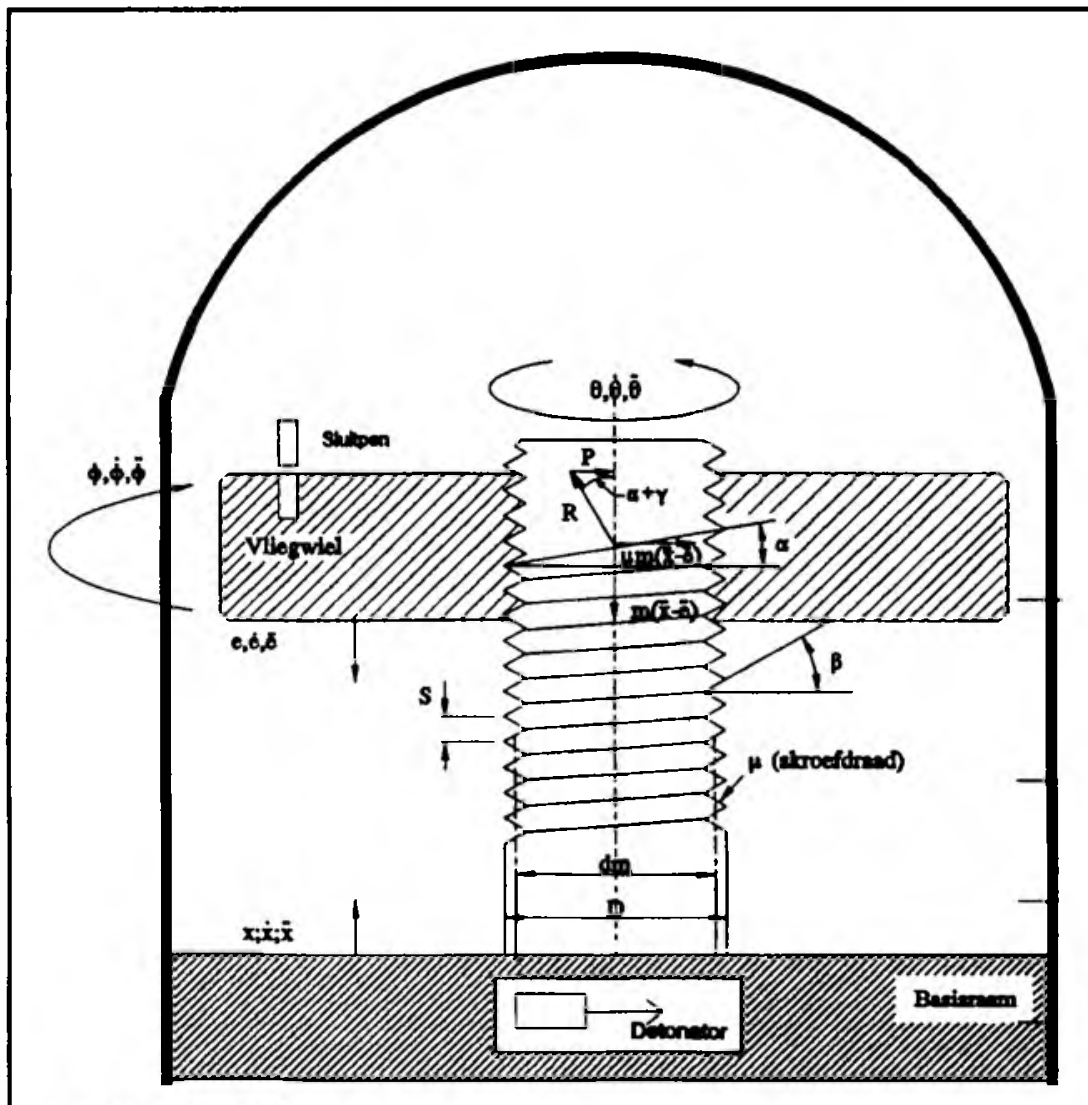

FIGUUR 1: Werking van die vliegwiel. 


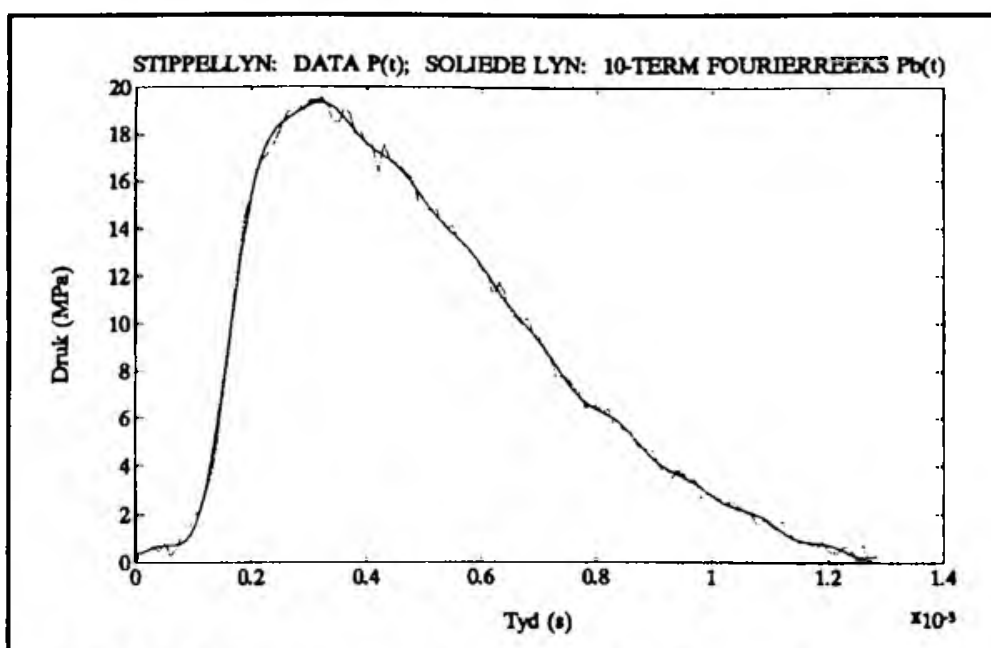

FIGUUR 2: Eksperimentele en benaderde drukkromme.

met 'n progressief toenemende loopgroefhoek. Die enigste aandryfkrag, naamlik die gasdruk in die loop agter die projektiel verkeer in balans met die rotasie- en translasietraagheidskragte, remkrag as gevolg van wrywing, teentolkrag as gevolg van wrywing en 'n drukkragverlies. Al die verliese word in een verliesterm saamgevat, wat volgens industriële bronne vir hierdie wapens om en by tien persent van die oombliklike aandryfkrag beloop.

\section{Fisiesekragte-ontleding}

Die volgende vergelyking vir die oombliklike drukkrag $\mathbf{P}(\mathbf{t}) \mathbf{A}$ in die loop word met behulp van figuur 3 as model opgestel, met $\mathrm{N}$, die normaalkrag op die loopgroef gelyk en teenoorgesteld in rigting aan die reaksiekrag $R$, van die loopgroef op die projektiel. Die lekverliese $\mathrm{V}$ van die hoëdruk-detonasiegasse word ook as 'n faktor in berekening gebring en die wrywingskoëffisiënt tussen die projektiel- en die loopmateriale is $\mu_{t}$ sodat

$$
\begin{aligned}
P(t) A= & P(t) A \operatorname{Cos}^{2} \varepsilon+P(t) A \operatorname{Cos} \varepsilon \operatorname{Sin} \varepsilon-\mu_{l} R \operatorname{Cos} \varepsilon- \\
& \mu_{l} R \operatorname{Sin} \varepsilon-V
\end{aligned}
$$

Die benaderde druk $P_{b}(t)$ wat deur 'n Fourierreekspassing verkry is, word in die vergelyking gebruik. Die dryf- of drukkrag is die produk van die benaderde druk $\mathrm{P}_{b}(l)$ en die dwarssnitarea A van die projektiel of loop.

Dus

$$
P_{b}(t) A=P_{b}(t) A \operatorname{Cos}^{2} \varepsilon+P_{b}(t) A \operatorname{Cos} \varepsilon \operatorname{Sin} \varepsilon+F r
$$

met Fr wat al die verliesterme insluit sodat

$$
F r=-u_{l} R \operatorname{Cos} \varepsilon-u_{l} R \operatorname{Sin} \varepsilon-V
$$

\section{Dinamiesekragbalans}

Die projektielversnelling in terme van translasie en rotasie is die gevolg van die drukkrag minus die verliesterm. Vir'n projektiel met diameter $\mathrm{D}$, traagheid I, massa $\mathrm{M}$, traagheidstraal $\mathrm{r}_{\mathrm{T}}$ en onderhewig aan ' $\mathrm{n}$ draaimoment $\mathrm{T}$ om rotasioneel te versnel met $\ddot{\theta}(t)$ en lineêr met $\tilde{x}(t)$ geld die volgende verwantskap:

$$
P_{b}(t)\left(\frac{\pi D^{2}}{4}\right)=M \ddot{x}(t)+\frac{2 M r_{r}^{2} \ddot{\theta}(t)}{D}+F r
$$

Vir 'n oomblikswaarde van $P_{b}$ kan die algemene differen- siaalvergelyking soos volg herrangskik word om die translasieversnelling te bepaal vir elke tydstip t:

$$
\ddot{x}(t)=\frac{P_{b}(t)\left(\frac{\pi D^{2}}{4}\right)}{M}-\frac{2 r_{\tau}^{2} \theta(t)}{D}-\frac{F r}{M}
$$

Die spesifieke differensiaalvergelykings vir elke loopgedeelte word dan verkry deur die ooreenkomstige verwantskappe van rotasie teenoor translasie, met inbegrip van die snelheids- en versnellingsverwantskappe, in vergelyking 4 te vervang.

Loopgedeelte met reguit groewe; $x \boldsymbol{\varepsilon}(0 ; 0,04)$.

Geen rotasie vind in hierdie gebied plaas nie, sodat

$$
\theta(t)=\dot{\theta}(t)=\ddot{\theta}(t)=0
$$

dus word vergelyking 4 herskryf na

$$
\ddot{x}(t)=\frac{F_{b}^{\prime}(t)\left(\frac{\pi D^{2}}{4}\right)-F r}{M}
$$

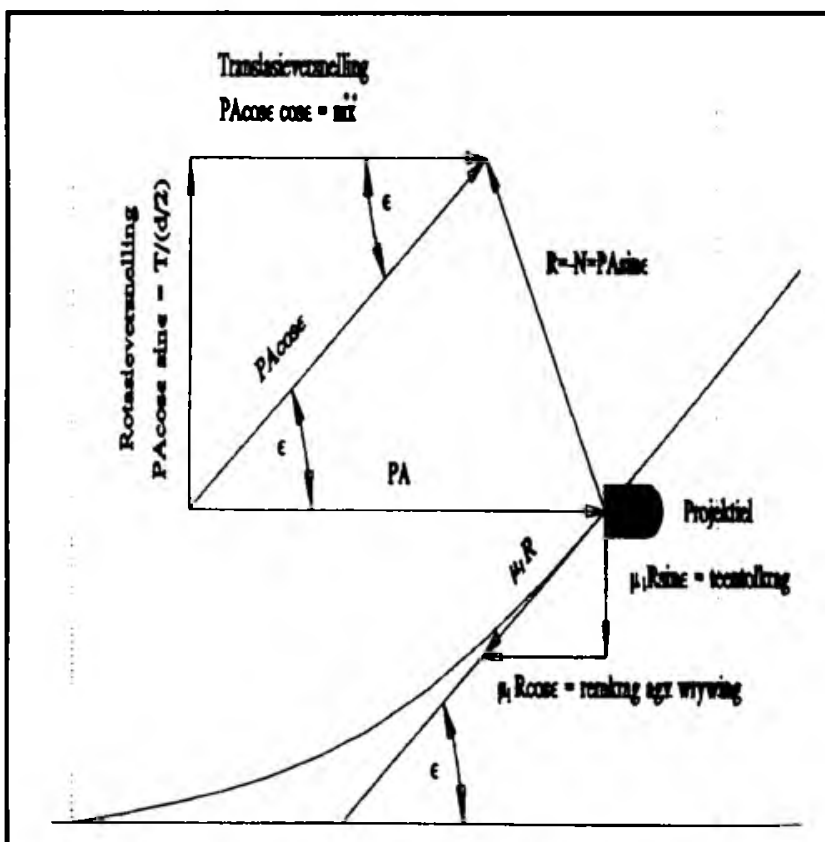

FIGUUR 3: Modellering van projektielbeweging. 
Loopgedeelte met toenemende loopgroefhoek; $x \in(0,04$; $0,24)$.

Loopgroefverwantskappe vir hierdie gebied word in vergelyking 4 vervang en herrangskik om die volgende oplosbare differensiaalvergelyking te verkry:

$$
\begin{aligned}
\ddot{x}(t)= & \frac{P_{b}(t)\left(\frac{\pi D^{2}}{4}\right)-F r}{M+\frac{2 M r_{T}^{2}}{D} c n x^{n-1}}-\frac{2 M r_{T}^{2}}{M+\frac{2 M r_{T}^{2}}{D} c n x^{n-1}} . \\
& \left.\left(c n(n-1) x^{n-2} / \dot{x}(t)\right]^{2}\right)
\end{aligned}
$$

Loopgedeelte met konstante loopgroefhoek; $x \in(0,24 ; 0,3)$.

Ooreenkomstige loopgroefverwantskappe vir die gebied word in vergelyking 4 vervang en die veranderlikes geskei om 'n maklik oplosbare differensiaalvergelyking te verkry:

$$
\ddot{x}(t)=\frac{P_{b}(t)\left(\frac{\pi D^{2}}{4}\right)-F r}{M+\frac{2 M r_{T}^{2}}{D} \cdot c}
$$

Die oplossings van vergelykings 6 en 7 word met behulp van Butcher se vyfde orde Ruge Kutta-metode gedoen, met spesifieke beginwaardes en -groothede vir 'n spesifieke wapen.

\section{Wiskundige model van projektielbeweging tydens} eksterne ballistiese fase

Wanneer die projektiel die loop verlaat, sal dit onderworpe wees aan lugweerstand wat ' $n$ invloed uitoefen op sowel translasie- as rotasiebeweging. Dit is algemene praktyk om die rotasievertraging, net soos die swaartekragversnelling, buite rekening te laat met dinamiese aanslagbuisontwerpe vir hierdie fase, omdat albei se invloed op enige van die buisonderdele, ordes kleiner is as die ander beheerkragte.

Volgens Daugherty \& Franzini ${ }^{2}$ veroorsaak lugweerstand egter 'n sleepkrag wat afhanklik is van die projektiel se oombliklike snelheid, frontale oppervlakte, vorm en massa en van die heersende atmosferiese toestande soos lugdruk en temperatuur. Die onderlinge verband word soos volg beskryf waar $F_{D}$ die sleurkrag, $\rho$ die lugdigtheid, $D$ die projektieldiameter, $C_{D}$ die sleurkragkoëffisiënt en $\dot{x}(t)$ die projektielsnelheid voorstel:

$$
F_{D}=\rho \frac{\mu D^{2}}{8} C_{D}[\dot{x}(t)]^{2}
$$

maar dit moet volgens Newton se Wet balanseer met die vertragingskrag sodat

$$
F_{D}=-a M=-\ddot{x}(t) M
$$

wat die vergelyking vir die translasievertraging buite die loop gee as

$$
\ddot{x}(t)=-\frac{\rho \pi \mu D^{2}}{8 M} C_{D}[\dot{x}(t)]^{2}
$$

Uit hierdie differensiaalvergelyking kan die versnelling vir elke tydstip bereken word as die $C_{D}$-waarde vir 'n projektiel bekend is of eksperimenteel bepaal is.

\section{Vliegwielsamestelling}

In figuur 1 word die fisiese model met al die bewegingskragte wat 'n rol speel op die vliegwielgedrag voorgestel. Die vliegwiel sal relatief roteer met 'n hoekverplasing $\Phi$, hoeksnelheid $\dot{\Phi}$ en hoekversnelling $\dot{\phi}$ om die basisraam se as met ' $n$ bepaalde skroefdraad van gemiddelde diameter $d_{m}$ ' wrywingskoëffisiënt $\mu$ en skroefdraadsteekafstand s. Die vliegwiel sal vorentoe of agtertoe beweeg binne-in die neusbuis, afhangende van die skroefdraadkeuse naamlik linkerhandse (LH) of regterhandse (RH) draad, sodat die relatiewe verplasing daarvan weergegee word as ' $n$ veranderlike e met relatiewe translasiesnelneid $\dot{e}$ en relatiewe translasieversnelling $\ddot{e}$.

Sowel die rotasie- as translasiebeweging van die vliegwiel is as gevolg van die projektiel se rotasieversnelling $\ddot{\theta}$ en translasieversnelling $\ddot{x}$ wat dit binne die loop en daarna buite die loop ondervind. Hierdie relatiewe verplasing van die vliegwiel in die neusbuis kan gebruik word om sekere funksies te verrig, soos ontsluiting by terugslag en rotasiebewapening met tydvertraging, wat tipies ' $n$ veilige bewapeningsafstand sal verseker.

Die vliegwiel roteer egter as gevolg van die wrywingskrag $P$, wat dit probeer meehelp tydens relatiewe rotasie. Hierdie wrywingskrag is afhanklik van die massa $m$ van die vliegwiel, die heliese hoek $\alpha$ van die skroefdraad en die skroefdraadhoek $B$ vir enige skuins tipe skroefdraad. Verder word $P$ slegs beïnvloed deur die relatiewe translasieversnelling en die wrywingskoëffisiënt tussen die vliegwiel en projektielas terwyl die relatiewe rotasieversnelling geen invloed daarop het nie.

Volgens Shigley ${ }^{3}$ word die volgende vergelykings afgelei vir heliese skroefdrade met 'n skroefdraadsteekafstand s en skuins skroefdraadprofiele vir linkerhandse en regterhandse skroefdrade.

Vir skroefaksie teen die lasrigting word die draaimoment wat op die gemiddelde diameter $d_{m}$ uitgeoefen word, met ' $n$ normaalkrag $N=m(\ddot{x}-\dot{e})$, gegee deur

$$
\mathrm{T}_{\mathrm{F}}=\frac{m(\ddot{x}-\ddot{e}) d_{m}}{2}\left(\frac{\tan \alpha+\frac{\mu}{\operatorname{Cos} \delta}}{1-\frac{\mu \tan \alpha}{\operatorname{Cos} \delta}}\right)
$$

Vir skroef saam met die lasrigting word die draaımoment wat op die gemiddelde diameter $d_{m}$ uitgeoefen word, met ' $n$ vertikale normaalkrag $\mathrm{N}$ gegee deur

$$
\mathrm{T}_{\mathrm{F}}=\frac{m(\not{x}-\ddot{e}) d_{m}}{2}\left(\frac{-\tan \alpha+\frac{\mu}{\operatorname{Cos} \delta}}{1+\frac{\mu \tan \alpha}{\operatorname{Cos} \delta}}\right)
$$

Die hoek delta is 'n funksie van die heliese hoek $\alpha$ en die skroefdraadprofielhoek $B$ sodat

$$
\delta=b g \tan (\tan \beta . \operatorname{Cos} \alpha)
$$

waar die heliese hoek verkry word deur die tangens van skroefdraadsteek $s$ en die omtrek van die skroefdraad te bepaal:

$$
\tan \alpha=\frac{s}{\pi d_{m}}
$$


Die beskikbare draaimoment as gevolg van die projektiel se rotasieversnelling $\ddot{\theta}$, wat inwerk op die traagheid van die vliegwiel I, word gegee deur

$$
T=-I \ddot{\theta}
$$

Die rotasieversnelling $\ddot{\phi}$ van die vliegwiel relatief tot die projektielas word gegee deur

$$
T_{r}=I \Phi
$$

Die netto rotasieversnelling van die vliegwiel in dieselfde rigting as die rotasieversnelling $\ddot{\theta}$ van die projektiel is slegs toe te skryf aan wrywing. Dus kan die relatiewe hoekversnelling $\Phi$ tussen die vliegwiel en die projektiel soos volg afgelei word:

$$
\begin{aligned}
& T_{r}=T+T_{F} \\
& \therefore I \dot{\Phi}=-I \ddot{\theta}+T_{F}
\end{aligned}
$$

vir skroef teen die lasrigting

$$
\therefore \ddot{\Phi}=-\ddot{\theta}+\frac{m(\ddot{x}-\ddot{e}) d_{m}}{2 I}\left(\begin{array}{c}
\tan \alpha+\mu \\
\frac{\operatorname{Cos} \delta}{1-\mu \tan \alpha} \\
\operatorname{Cos} \delta
\end{array}\right)
$$

vir skroef saam met die lasrigting

$$
\ddot{\Phi}=-\ddot{\theta}+\frac{m(\tilde{x}-\ddot{e}) d_{m}}{2 I}\left(\frac{-\tan \alpha+\mu}{\frac{\operatorname{Cos} \delta}{\operatorname{Cos} \delta}}\right)
$$

met 'n lineêre verband tussen $\phi$ en e wat soos volg weergegee word vir skroefdrade met konstante steekafstande waar $\mathbf{s}$ tipies die steekafstand of skroefdraadstyging per omwenteling voorstel:

$$
\begin{aligned}
\ddot{e} & =\frac{s}{2 \pi}(-\Phi) \\
\dot{e} & =\frac{s}{2 \pi}(-\dot{\Phi}) \\
e & =\frac{s}{2 \pi}(-\Phi)
\end{aligned}
$$

\section{RESULTATE EN BESPREKING}

Die rekenaarprogram wat ontwikkel is vir simulasiedoeleindes benodig numeriese insette. Al die parameters word vooraf bereken en ingelees saam met die drukpulskoëffisiënte deur middel van insetleêrs. Die parameters word verdeel in loopparameters, projektielparameters en vliegwielparameters.

\section{Loopparameters}

Drukpulskoëffisiënte soos in 3.2 bereken, word ingelees. Loopgroefkonstantes $\mathbf{m}$, $\mathbf{n}$ en $\mathbf{c}$ word bereken en ingelees. Trajekgebiede van projektiel word ingelees.

Reguit groewe: $\quad x(a)=0,04(\mathrm{~m})$

Toenemende groewe: $x(b)=0,24(\mathrm{~m})$

Konstante groewe: $x(c)=0,30(\mathrm{~m})$

Reikafstand: $\quad x(d)=400(m)$

\section{Projektielparameters}

Diameter: $D=0,04(\mathrm{~m})$

Massa: $M=0,175(\mathrm{~kg})$

Ekwivalente traagheidstraal: $r_{T}=0,016(\mathrm{~m})$

Drukkragverlies: $\mathrm{Fr}=0,05$

Sleurkoëffisiënt: $C_{D}=0,231$ (gegee) $\mathrm{I}=0,0000448 \mathrm{kgm}^{2}$

\section{Vliegwielparameters}

Massa: $m=0,013587(\mathrm{~kg})$

Traagheidsmoment: $I=9,783145 \times 10^{-7}\left(\mathrm{kgm}^{2}\right)$

Skroefdraaddiameter: $d=0,006(\mathrm{~m})$

Skroefdraadwrywingskoeffisiěnt: $\mu=0,2$

Heliese hoekverhouding: $\tan \alpha=s / \pi \mathrm{d}$

Skroefdraadprofielhoek: $B=30^{\circ}$

Skroefdraadsteek: $s=0,001(\mathrm{~m})$

\section{Resultate}

Resultate soos bereken met behulp van 'n rekenaarprogram word in tabelvorm opgesom vir die hele projektielbaan vanaf afvuring tot en met die moontlike reikafstand van $\mathbf{4 0 0}$ meter, as daar byvoorbeeld geen botsing sou plaasvind nie. Die tabelle vertoon die onderskeie verplasings, snelhede en versnellings vir elke differensiaalvergelyking in opeenvolgende kolomme, soos bereken met behulp van die genoemde oplosmetode, wat deel vorm van die rekenaarprogram. Die verplasing, snelheid en versnelling vir elke differensiaalvergelyking word telkens vir elke tiende berekeningstap (i) en die ooreenkomstige tydstip t(i) in tabelle 1 en 2 aangedui. Binne die loop is die tydstappe baie kort gekies, naamlik 25,7 mikrosekondes om die gedrag van die projektiel en die verskillende meganismes telkens akkuraat te bepaal na verloop van 'n kort afstand van minder as een millimeter. Buite die loop is toestande minder ekstreem en die tydstappe vir berekeninge is aanvanklik as millisekondes en later as tiendes van sekondes geneem.

Daar word op die tabelle aangedui by watter tydstip $t(i)$ veranderings of oorgangstoestande plaasvind. Opmerkings dui die posisies aan waar die translasiesnelheid ' $n$ maksimum is en later wanneer die translasieversnelling negatief word, waar die loopgroefhoek verander of die projektiel die loop verlaat of laastens waar bewapening afgehandel is. Meer as 300 berekeningstappe is opeenvolgend gebruik, wat genoegsame akkuraatheid lewer om die gedrag van die neusbuis oor die hele trajek te simuleer. Meer stappe kan baie maklik bygevoeg word indien nog groter akkuraatheid verlang word.

\section{Bespreking van resultate}

Deur gebruik te maak van ' $n$ wiskundige verwerkingspakket, word die berekende resultate, soos voorgestel in tabelle 1 en 2 , verwerk. Die tydsverloop en translasieverplasing vorm die basis waarteenoor alle ander parameters grafies geplot word.

Die verplasings, snelhede en versnellings vir binne en buite die loop gemeet teen tydsverloop is nuttig as oomblikswaardes om tipies sekere detailontwerpparameters mee te bepaal. Dit dui verder ook aan wanneer iets met die projektiel en die meganismes binne die neusbuis gebeur. Die simulasie transformeer onder andere die verplasings, snelhede en versnellings na funksies van projektielverplasing, 
sodat 'n geheelbeeld verkry word van projektiel- en meganismegebeure binne die neusbuis.

\section{Projektieltranslasie}

Die projektiel versnel baie vinnig tot 'n maksimum waarde van ongeveer $130000 \mathrm{~m} / \mathrm{s}^{2}$ gedurende die eerste $1 \mathrm{~mm}$ verplasing, waarna dit weer drasties afneem tot nul by ongeveer $50 \mathrm{~mm}$, soos blyk uit tabel 1. Dit stem ooreen met die benaderde drukpulsprofiel in figuur 2. Die loopgroefspiraal begin by $40 \mathrm{~mm}$ en veroorsaak ' $\mathrm{n}$ aansienlike translasievertraging. $\mathrm{Na} 50 \mathrm{~mm}$ verval die drukkrag ook na benaderd nul. 'n Gedeelte van die translasie-energie word dus in rotasie-energie omgesit, sodat die snelheid afneem vanaf $58 \mathrm{~mm}$ tot waar die eksponensièle loopgroewe oorgaan in konstante loopgroewe by $240 \mathrm{~mm}$. Vir die res van die loopgedeelte tot by $300 \mathrm{~mm}$ is die translasieversnelling nul en bly die snelheid konstant op $68,2 \mathrm{~m} / \mathrm{s}$.

Buite die loop blyk dit dat die projektiel stadiger en nielineêr vertraag oor die vlugtyd van $7 \mathrm{~s}$. Dit is voorspelbaar, omdat slegs 'n lugweerstandskrag daarop inwerk. Hierdie negatiewe versnelling veroorsaak dat die snelheid afneem tot ongeveer $48,9 \mathrm{~m} / \mathrm{s}$ na $400 \mathrm{~m}$, soos aangedui in tabel 1 .

\section{Projektielrotasie}

Soos reeds afgelei, is die projektielrotasie binne die loop gekoppel aan die translasie van die projektiel. Vir die eerste $40 \mathrm{~mm}$ van die loop roteer die projektiel glad nie, waarna die rotasie eksponensieel toeneem tot by $240 \mathrm{~mm}$ en dan ' $\mathrm{n}$ konstante verhouding tussen hoekverplasing en translasieverplasing handhaaf.

Buite die loop word lugweerstand op die projektiel se rotasiesnelheid verwaarloos, sodat geen rotasievertraging plaasvind nie en die rotasiesnelheid dus dieselfde bly as vir die laaste $60 \mathrm{~mm}$ binne die loop, naamlik $3415,8 \mathrm{opm}$ vir die res van die vlug.

\section{Vliegwielgedrag}

Die vliegwielbeweging word direk beïnvloed deur die projektiel se translasieversnelling, rotasiesnelheid en rotasieversnelling. Die beginwaarde vir vliegwielrotasie en gevolglik ook die vliegwieltranslasie is gelyk aan nul vir die eerste $40 \mathrm{~mm}$ van die projektiel se verplasing, soos getoon deur die berekende resultate in tabel 2 .

Die vliegwielrotasie gaan voort na bewapening, terwyl translasie ' $n$ beperking van $10 \mathrm{~mm}$, met ' $n$ toleransie van 0,5

TABEL 1 Translasie van projektiel

\begin{tabular}{|c|c|c|c|c|c|}
\hline $\begin{array}{c}\text { Stap } \\
\text { no. }\end{array}$ & $\begin{array}{c}\text { Tydstip } \\
\text { (s) }\end{array}$ & $\begin{array}{l}\text { Afstand } \\
\text { (m) }\end{array}$ & $\begin{array}{c}\text { Translasie- } \\
\text { snelheid } \\
(\mathrm{m} / \mathrm{s})\end{array}$ & $\begin{array}{l}\text { Translasie- } \\
\text { versnelling } \\
\left(\mathrm{m} / \mathrm{s}^{2}\right)\end{array}$ & Opmerkings \\
\hline $\begin{array}{r}1 \\
10 \\
20 \\
30 \\
40 \\
50 \\
60 \\
70 \\
80 \\
90 \\
100 \\
110 \\
120 \\
130 \\
140 \\
150 \\
160 \\
170 \\
180 \\
190 \\
200 \\
210 \\
220 \\
230 \\
240 \\
250 \\
260 \\
270 \\
280 \\
290 \\
300 \\
310 \\
320 \\
326\end{array}$ & $\begin{array}{c}, 0000257 \\
, 0002570 \\
, 0005140 \\
, 0007710 \\
, 001028 \\
, 001285 \\
, 001542 \\
, 001799 \\
, 002056 \\
, 002313 \\
, 002570 \\
, 002827 \\
, 003084 \\
, 003341 \\
, 003598 \\
, 003855 \\
, 004112 \\
, 004369 \\
, 004626 \\
, 004883 \\
, 005140 \\
, 005397 \\
, 035500 \\
, 085500 \\
, 135500 \\
, 185500 \\
, 425500 \\
1,4255 \\
2,4255 \\
3,4255 \\
4,4255 \\
5,4255 \\
6,4255 \\
7,0255\end{array}$ & $\begin{array}{c}, 00000087 \\
, 0007593 \\
, 0081397 \\
, 022117 \\
, 0395 \\
, 0580 \\
, 0766 \\
, 0952 \\
, 1136 \\
, 1320 \\
, 1502 \\
, 1683 \\
, 1863 \\
, 2042 \\
, 2219 \\
, 2395 \\
, 2570 \\
, 2746 \\
, 2921 \\
, 3096 \\
, 3271 \\
, 3447 \\
2,396 \\
5,795 \\
9,185 \\
12,565 \\
28,661 \\
93,513 \\
155,069 \\
213,646 \\
269,519 \\
322,929 \\
374,081 \\
403,767\end{array}$ & $\begin{array}{l}\mathbf{1} 076 \\
12,512 \\
43,608 \\
62,834 \\
70,797 \\
72,609 \\
72,330 \\
71,986 \\
71,597 \\
71,174 \\
70,723 \\
70,251 \\
69,762 \\
69,259 \\
68,745 \\
68,222 \\
68,199 \\
68,199 \\
68,199 \\
68,198 \\
68,198 \\
68,197 \\
68,081 \\
67,890 \\
67,701 \\
67,512 \\
66,621 \\
63,147 \\
60,017 \\
57,183 \\
54,604 \\
52,248 \\
50,087 \\
48,874\end{array}$ & $\begin{array}{c}3923,06 \\
126725,40 \\
100521,50 \\
47112,88 \\
16290,14 \\
1097,29 \\
-1234,43 \\
-1434,81 \\
-1585,31 \\
-1703,11 \\
-1797,04 \\
-1872,44 \\
-1932,91 \\
-1981,05 \\
-2018,81 \\
-2047,74 \\
0 \\
0 \\
0 \\
-3,84 \\
-3,84 \\
-3,84 \\
-3,83 \\
-3,81 \\
-3,78 \\
-3,76 \\
-3,67 \\
-3,29 \\
-2,97 \\
-2,70 \\
-2,46 \\
-2,25 \\
-2,07 \\
-1,97\end{array}$ & $\begin{array}{l}\text { Maksimum } \\
\text { versnelling } \\
\text { Maksimum snelheid }\end{array}$ \\
\hline
\end{tabular}


$\mathrm{mm}$ het. Hierdie fisiese beperking beteken dat die relatiewe translasieversnelling en -snelheid van die vliegwiel na bewapening gelyk aan nul bly tot aan die einde van die vlug, omdat die vliegwiel die skroefdraad verlaat het en vry roteer.

Binne die loop word die relatiewe rotasie (gliphoek) van die vliegwiel, wat negatief ten opsigte van projektielrotasie is, grafies deur figuur 4 voorgestel. Die relatiewe rotasie is gelyk aan nul vir die eerste $40 \mathrm{~mm}$ waar die loopgroewe reguit is, waarna die projektielrotasiesnelheid, soos reeds bespreek, eksponensieel toeneem. Hierdie toename veroorsaak dat die relatiewe hoeksnelheid van die vliegwiel eksponensieel toeneem in 'n negatiewe rigting, soos blyk uit figuur 5, omdat die skroefdraadwrywingskrag nagenoeg konstant bly. Vir die laaste deel van die loop, vanaf $240 \mathrm{~mm}$ tot 300 $\mathrm{mm}$, is die relatiewe hoeksnelheid van die vliegwiel konstant. Die relatiewe verplasing en translasiesnelheid van die vliegwiel vertoon ooreenkomstige gedrag, maar in 'n positiewe rigting, omdat dit so gedefinieer is.

Die relatiewe hoekversnelling van die vliegwiel binne die loop vertoon rukbewegings by $40 \mathrm{~mm}$ en $240 \mathrm{~mm}$, soortgelyk aan die wat voorkom by nokvolgers in enjins, soos in figuur 6 getoon. Dit is toe te skryf aan skielike

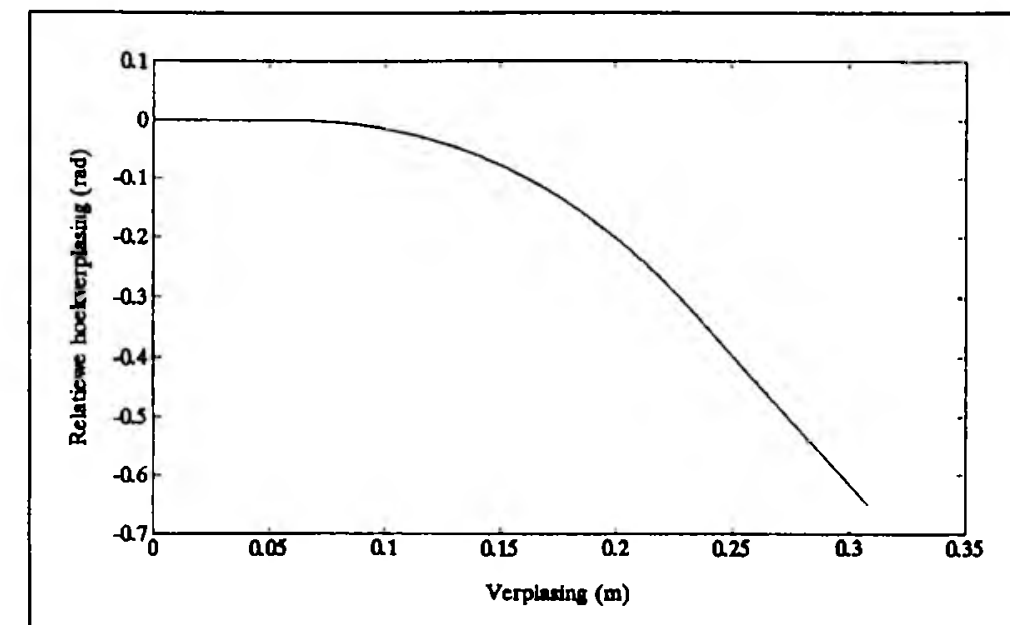

FIGUUR 4: Relatiewe hoekverplasing van vliegwiel teen projektielverplasing (binne die loop).

TABEL 2 Relatiewe rotasie van vliegwiel

\begin{tabular}{|c|c|c|c|c|c|}
\hline $\begin{array}{l}\text { Stap } \\
\text { no. }\end{array}$ & $\begin{array}{c}\text { Tydstip } \\
\text { (s) }\end{array}$ & $\begin{array}{c}\text { Rotasie } \\
\text { (rad) }\end{array}$ & $\begin{array}{c}\text { Rotasie- } \\
\text { snelheid } \\
(\mathrm{rad} / \mathrm{s})\end{array}$ & $\begin{array}{c}\text { Rotasie- } \\
\text { versnelling } \\
\left(\mathrm{rad} / \mathrm{s}^{2}\right)\end{array}$ & Opmerkings \\
\hline $\begin{array}{r}1 \\
10 \\
20 \\
30 \\
40 \\
50 \\
60 \\
70 \\
80 \\
90 \\
100 \\
110 \\
120 \\
130 \\
140 \\
150 \\
160 \\
170 \\
180 \\
190 \\
200 \\
210 \\
220 \\
230 \\
240 \\
250 \\
260 \\
270 \\
280 \\
290 \\
300 \\
310 \\
320 \\
326\end{array}$ & $\begin{array}{c}, 0000257 \\
, 0002570 \\
, 0005140 \\
, 0007710 \\
, 001028 \\
, 001285 \\
, 001542 \\
, 001799 \\
, 002056 \\
, 002313 \\
, 002570 \\
, 002827 \\
, 003084 \\
, 003341 \\
, 003598 \\
, 003855 \\
, 004112 \\
, 004369 \\
, 004626 \\
, 004883 \\
, 005140 \\
, 005397 \\
, 035500 \\
, 085500 \\
, 135500 \\
, 185500 \\
, 425500 \\
1,4255 \\
2,4255 \\
3,4255 \\
4,4255 \\
5,4255 \\
6,4255 \\
7,0255\end{array}$ & $\begin{array}{c}0 \\
0 \\
0 \\
0 \\
0 \\
-0,0004 \\
-0,0026 \\
-0,0011 \\
-0,0259 \\
-0,0477 \\
-0,0772 \\
-0,1146 \\
-0,1603 \\
-0,2146 \\
-0,2777 \\
-0,3498 \\
-0,4268 \\
-0,5038 \\
-0,5808 \\
-0,6578 \\
-0,7348 \\
-0,8118 \\
-9,8116 \\
-24,6760 \\
-39,4360 \\
-54,0922 \\
-123,015 \\
-385,929 \\
-612,667 \\
-806,731 \\
-971,139 \\
-1108,505 \\
-1221,116 \\
-1277,645\end{array}$ & $\begin{array}{c}0 \\
0 \\
0 \\
0 \\
0 \\
-2,67 \\
-21,67 \\
-44,84 \\
-71,02 \\
-99,49 \\
-129,78 \\
-161,54 \\
-194,46 \\
-228,32 \\
-262,92 \\
-298,09 \\
-299,63 \\
-299,63 \\
-299,63 \\
-299,63 \\
-299,61 \\
-299,60 \\
-298,34 \\
-296,24 \\
-294,16 \\
-292,09 \\
-282,31 \\
-244,20 \\
-209,86 \\
-178,77 \\
-150,48 \\
-124,63 \\
-100,92 \\
-87,61\end{array}$ & $\begin{array}{c}0 \\
0 \\
0 \\
0 \\
0 \\
-66838,28 \\
-83064,97 \\
-96548,66 \\
-106676,10 \\
-114602,90 \\
-120923,30 \\
-125997,20 \\
-130066,50 \\
-133305,50 \\
-135846,40 \\
-137793,30 \\
0 \\
0 \\
0 \\
42,13 \\
42,14 \\
42,14 \\
41,99 \\
41,75 \\
41,52 \\
41,29 \\
40,21 \\
36,13 \\
32,63 \\
29,62 \\
27,01 \\
24,73 \\
22,73 \\
21,64\end{array}$ & $\begin{array}{l}\text { Loopgroefhoek } \\
\text { eksponensieel }\end{array}$ \\
\hline
\end{tabular}


oorgange waar die loopgroefhoek oorgaan van reguit groewe na groewe waarvan die hoek eksponensieel toenemend is vanaf $40 \mathrm{~mm}$ tot by $240 \mathrm{~mm}$ en dan verder konstant bly tot aan die einde van die loop. Hierdie oorgange is skielik en by spesifieke posisies, sodat hewige versnellings opgewek word, maar dit het min invloed op die snelheidsoorgange by $40 \mathrm{~mm}$ waar slegs 'n klein piek te sien is, soos in figuur 5 geilllustreer. Uit die grafiese voorstelling van relatiewe hoekverplasing van die vliegwiel teenoor projektielverplasing in figuur 4 , is dit duidelik dat die rukbewegings geen invloed het ten opsigte van die vliegwiel se relatiewe rotasie nie.

Die negatiewe waarde van die relatiewe hoekverplasing (gliphoek) van die vliegwiel styg nie-eenvormig met verloop van tyd vir die fase buite die loop, soos blyk uit tabel 2. Dit gebeur ten spyte daarvan dat die projektiel se rotasieversnelling gelyk aan nul is, omdat die projektiel nog steeds vinniger roteer as die vliegwiel.

Die relatiewe verplasing van die vliegwiel styg vinnig en reglynig met betrekking tot projektielverplasing, omdat die fase binne die loop min bydra tot die totale hoekverplasing, maar dit bewerkstellig die verskil in rotasiesnelhede van die projektiel en die vliegwiel. Die relatiewe vliegwieltranslasie word egter beperk deur die gegewe randwaarde van $10 \mathrm{~mm}$, sodat dit by ongeveer $15 \mathrm{~m}$ bereik word, waar dit finaal afgeskroef het tot onder om die bewapening af te handel.

\section{GEVOLGTREKKINGS}

Die gevolgtrekkings en waarnemings is tweeledig, naamlik die projektielbeweging as gevolg van loopgroefspesifikasie en die vliegwielgedrag as gevolg van projektielbeweging.

\section{Projektielbeweging}

'n Model is afgelei wat die projektielbeweging akkuraat simuleer binne die wapenloop. Dit is gedoen vir die algemeenste praktiese geval waar die loopgroefspesifikasie drie moontlikhede insluit wat mekaar opvolg. Ten spyte van die komplekse wiskundige verwantskappe is baie realistiese simulasieresultate verkry. Die rede hiervoor is dat daar eksakte verwantskappe bestaan vir die gegewe loopgroefspesifikasie.

Deur middel van die kettingreël is die verplasings-, snelheids- en versnellingsverwantskappe van die projektiel se translasie en rotasie getransponeer na 'n funksie van tyd, wat weereens eksak is en dus akkurate berekeninge lewer. Die gemeette drukpuls, wat die aandryfkrag vir die projektiel is, en die aanname ten opsigte van die verliesterm, mag die betroubaarheid van die model verminder, omdat dit kan verander vir ander plofstofladings en ander loopgroefmateriale.

\section{Vliegwielgedrag}

Die projektielbeweging dien as inset vir die neusbuis om die funksies van bewapening te verrig. Die projektielrotasie-

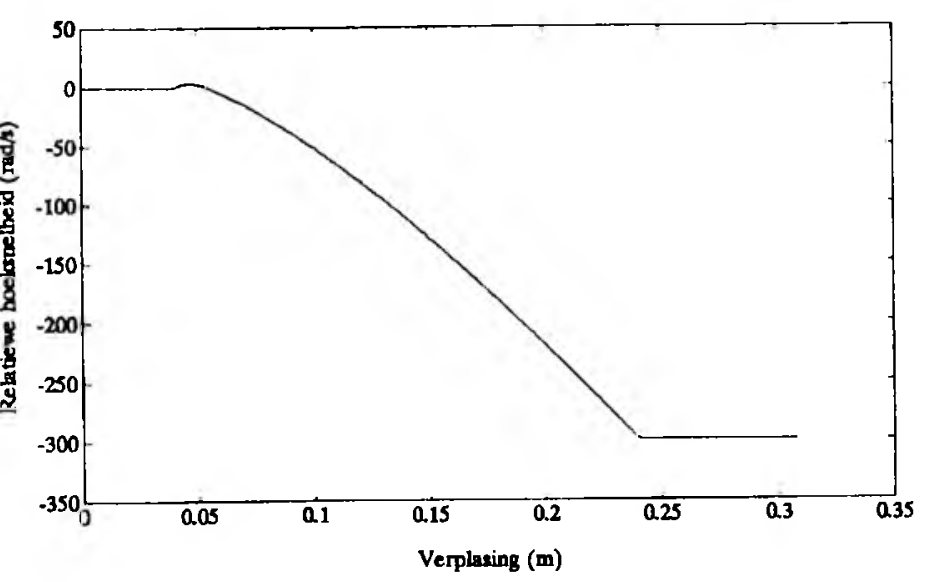

FIGUUR 5: Relatiewe hoeksnelheid van vliegwiel teen projektielverplasing (binne die loop).

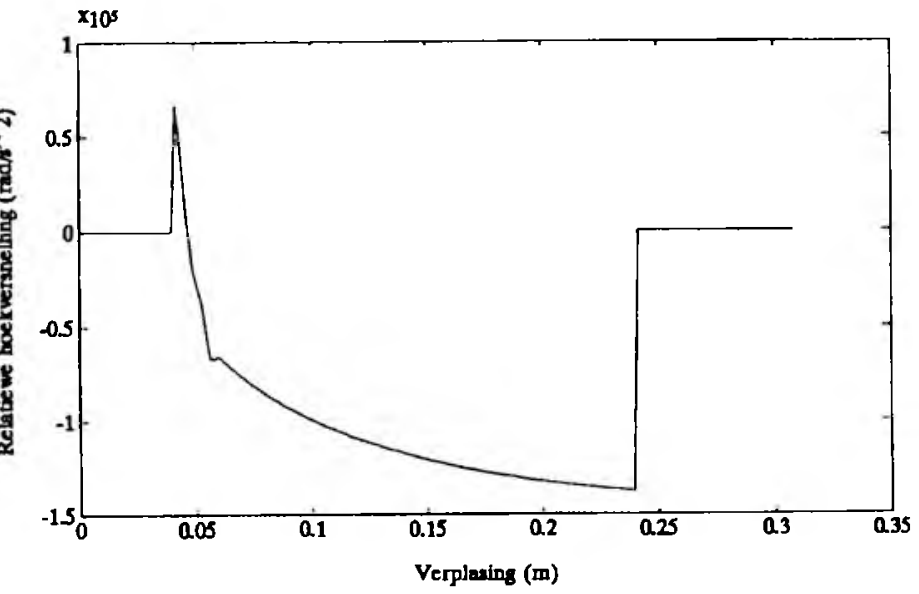

FIGUUR 6: Relatiewe hoekversnelling van vliegwiel teen projektielverplasing (binne die loop).

snelheid en -versnelling veroorsaak dat die vliegwiel op die skroefdraad glip en gevolglik in 'n omgekeerde rigting relatief tot die projektiel roteer, met gepaardgaande relatiewe rotasiesnelheid en -versnelling. Die aanvanklike verwagtings, naamlik dat die vliegwiel stadiger roteer as die projektiel en dat dit dus as 'n meetmeganisme gebruik kan word, is bevestig. Goeie simulasieresultate sonder wiskundige onstabiliteit, is verkry.

Die resultate toon dat die vliegwiel wel oor die bepaalde afstand in die verlangde tyd sal afskroef, om daarna die detonator te ontsluit. Die skielike veranderinge in die loopgroefhoek veroorsaak 'n skerp versnellingspiek, maar weens die kort tydsduur van die piek is die invloed op die snelheid van die vliegwiel weglaatbaar klein.

\section{Opsommend}

Hierdie simulasiepakket lewer spesifieke resultate vir 'n spesifieke grootte aanslagbuis en projektiel wat onder spesifieke toestande funksioneer. Die insette, bv. die plofstoflading, projektielmassa en/of projektieltraagheid, kan aangepas word, asook die parameters van die meganismes binne die buis, om soortgelyke stelsels te simuleer, mits dieselfde konsep vir die neusbuis gebruik word. Slegs geringe aanpassings sal in die rekenaarprogram nodig wees 
indien die drukpuls sou verander. Die simulasie kan ook as basis gebruik word indien die konsepontwerp aangepas, verander of uitgebrei word deur die simulasiepakket dienooreenkomstig aan te pas om byvoorbeeld groter of kleiner tipe ammunisie te simuleer of ammunisie met minder of meer funksies na te boots.

Ten spyte van die goeie simulasieresultate wat verkry is, moet daar egter op gelet word dat die bewapeningstyd onder andere ook 'n funksie van ' $n$ verliesterm en wrywing is. Die verliesterm is afhanklik van die projektielgeometrie, sowel as die druktoestande agter die projektiel en vorm nie deel van hierdie ondersoek nie. Hierdie twee faktore word egter in die praktyk goed beheer, omdat trompsnelheid van die projektiel binne nou grense gespesifiseer word. Wrywing tussen die vliegwiel en die skroefdraad is ook 'n faktor wat die model beïnvloed. Die resultate toon egter 'n lae gevoeligheid daarvoor. In die praktyk sal die bewapeningsafstand egter bepaal kan word deur die heliese of profielhoek van die skroefdraad aan te pas.

Die resultate wat verkry is, is so belowend dat hierdie tegniek ernstige oorweging deur ontwerpers regverdig.

\section{SUMMARY}

The main function of a fuse is to ensure that a round of ammunition, after being fired, will be armed after a safe distance of travelling from the point of firing. There is a need to develop a safe, reliable and affordable fuse as part of small callibre ammunition for smaller types of grenade launchers. A fuse is normally positioned at the front of a round of ammunition and causes self-arming of the round as a result of acceleration forces during translation and rotation. The fuse is also responsible for the detonation of the grenade on impact.

In this study different mechanisms, including alternative electronic systems for grenade-type rounds, are analyzed and the design of a unique fuse, which has never been used before, is presented. The fuse makes use of a flywheel-type mechanism controlled by time or distance of flight. Due to its simplicity of operation and construction, the concept is expected to have high reliability. In principle the fuse con- sists of a small fly wheel on a motion screw in the centre-line of the projectile. When the grenade is fired, the acceleration force ejects a lockpin which releases the flywheel allowing it to move freely on the screw. The flywheel rotates as a result of the friction between the internal and external threads of the flywheel and the centre shaft of the round which is exerted to rotational acceleration. However, the rotation of the flywheel is slower than the rotation of the round because of the inertia force action on the flywheel while it is accelerating. Consequently it unscrews along the shaft until, after a desired time, the grenade system is armed, ready for detonation on impact.

Mathematical models were developed for the movement of the projectile and all the mechanisms in the fuse. The projectile translation and rotational relationships as a result of barrel groove characteristics as well as the barrel groove friction forces and leakage as a function of the pressure pulse are included in the inputs to the model. The flywheel model takes all dynamic variables, such as the translation and rotational accelerations of the projectile as well as the counter acceleration of the flywheel as a result of the relative rotation, into account. All other parameters such as friction, inertia, mass, helix angle of the screw thread, profile angle and effective diameter also form part of the flywheel model that describes the flywheel behaviour in terms of rotation and translation in respect of displacement, speed and acceleration relationships.

The dynamic response of all the components of this flywheeltype fuse is simulated. Simulation software was developed, which connects the mathematical models of the various components. With the definition of boundary values, the response of the projectile, flywheel and other components can be determined continuously for firing and in-flight conditions.

\section{LITERATUURVERWYSINGS}

1. Kreyszig, E. (1972). Advanced engineering mathematics. 3rd ed. (John Wiley, New York).

2. Daugherty, R.L. \& Franzini, J.B. (1977). Fluid mechanics, with engineering applications. 7th ed. (McGraw-Hill).

3. Shigley, J.E. \& Mitchell, L.D. (1983). Mechanical engineering design. 4th ed. (McGraw-Hill). 